\title{
Establecimiento de una metodología para la visualización y conteo cromosómico en Phytophthora megakarya y Phytophthora palmivora, patógenos del cacao de África
}

\author{
Malena Martínezi,3, Michel Ducamp², \\ Samir Zambrano ${ }^{1,4}$, Mercedes Carranza ${ }^{1,3}$ \\ ${ }^{1}$ Unidad de Investigación Científica y Tecnológica, Laboratorio de Biotecnología y \\ Laboratorio Básico, Universidad Técnica Estatal de Quevedo. \\ Quevedo, Los Ríos, Ecuador. martinezmalena@yahoo.es \\ ${ }^{2}$ CIRAD, UMR BGPI. Campus Internationel de Baillarguet, Montpellier Cedex 5, Francia. \\ ${ }^{3}$ Facultad de Ciencias Ambientales, Universidad Técnica Estatal de Quevedo. \\ Quevedo, Los Ríos, Ecuador. \\ ${ }^{4}$ Facultad de Ciencias Agrarias, Universidad Técnica Estatal de Quevedo. \\ Quevedo, Los Ríos, Ecuador.
}

Recibido: 20, 05, 2011; aprobado: 26, 09, 2011

RESUMEN.- La "Mazorca Negra" es una enfermedad que afecta al cacao (Theobroma cacao L.), los agentes responsables son Phytophthora megakarya y Phytophthora palmivora. En África Central y Oeste, estos Oomycetes son responsables por la pérdida de más del $80 \%$ de producción. Esta investigación detalla una metodología estandarizada para la visualización y conteo de cromosomas de estas dos especies del género Phytophthora. El único órgano donde los cromosomas se diferencian en el momento de la meiosis es la "oospora"; de hecho, no se puede trabajar ni con los micelios ni con las esporas asexuales (esporangios y clamidosporas). Se ha mejorado las técnicas citológicas para obtención de oosporas; y la coloración nuclear "diamino -4, 6-phenylindol - 2 dichlorhydrate" (DAPI) jamás usada en los Oomycetes fue bien adaptada para visualizar los cromosomas de las dos especies de Phytophthora. Se contaron 5 a 6 cromosomas metafásicos en $P$. megakarya mientras que en P. palmivora entre 10 a 12. Sin embargo, se debe mejorar la técnica, separando la oospora de $P$. palmivora entre las esporas asexuales, para obtener un cultivo puro.

PALABRAS CLAVE.- Cromosomas, mazorca negra, oosporas, Phytophthora megakarya, Phytophthora palmivora. 
ABSTRACT.- Black pod disease affects cocoa growing worldwide: its pathogenic agents have been known for a long time and are Phytophthora megakarya and Phytophthora palmivora. These Oomycetes are responsible for a loss in production which can reach more than $80 \%$ in Central and West Africa. For the first time, this research has developed a standardized methodology for the visualization and chromosome counting of genus Phytophthora. The sole organ where chromosomes differentiate during meiosis is the "oospore"; consequently, we could not work with the mycelium or unsexed reproduction organs (sporocysts, chlamydospores). Improved techniques for obtaining oospores from both parasites were developed. Nuclear colouring with diamino -4, 6-phenylindol - 2 dichlorhydrate (DAPI) method was also improved for both species. This technique has never been previously completed for an Oomycete. The chromosomes in metaphase state were 5 to 6 in number in $P$. megakarya whereas in P. palmivora the chromosome number was between 10 and 12. It would be desirable to improve the technique regarding the separation of $P$. palmivora oospores from unsexed oospores, so that a pure culture can be obtained.

KEYWORDS: Chromosomes, black pod disease, oospores, Phytophthora megakarya, Phytophthora palmivora.

\section{INTRODUCCIÓN}

El cacao (Theobroma cacao L.) es originario de la cuenca del Amazonas, en las zonas comprendidas entre Colombia, Ecuador, Perú y Brasil. Por su origen y características genéticas, el cacao está clasificado en cuatro tipos: Criollo, Forastero Amazónico, Trinitario y Nacional de Ecuador. A inicios del siglo XIX fue introducido en África del Oeste, primer continente productor del cacao. La producción mundial anual 2010-2011 se estima que fue 3'938,000 TM, de las cuales 2'788,000 TM (70.8\%) correspondió a África, 548,000 TM (13.9\%) a América Latina y 602,000 TM (15.3 \%) a Asia (1).
Los países del África Central y Oeste están atravesando por dificultades de producción y expansión del cultivo, debido a la enfermedad "Mazorca Negra", causada por Phytophthora megakarya y Phytophthora palmivora. La pérdida de la producción se estima entre 40 a $80 \%$ debido a $P$. megakarya y entre 15 a $30 \%$ por P. palmivora (2).

La Mazorca Negra, es una enfermedad emergente que perturba gravemente la economía mundial del cacao. En África Nord-Oeste, P. megakarya está constituida como el principal agente causal de esta enfermedad, mientras que en América y Asia es $P$. palmivora (2). 
Los estudios cromosómicos son una herramienta importante y básica para el análisis intra e inter-poblacional, evolutivo y sistemática/taxonómico, permitiendo diferenciar especies morfológicamente similares o con un estado taxonómico incierto. Los conteos cromosómicos mitóticos y meióticos son usados frecuentemente para determinar las relaciones entre especies, análisis de cariotipos y translocaciones (3), además constituyen la vía más directa para establecer niveles de ploidía (4).

De igual manera, el análisis del ciclo celular permite determinar la mejor hora del día para la prefijación, en función del número de células en división y de los componentes del índice mitótico (5). Estos datos constituyen las herramientas principales para aumentar la efectividad de los métodos químicos y físicos para la visualización de cromosomas (6).

La presente investigación presenta el establecimiento de una metodología que permite la visualización de fases celulares y cromosomas metafásicos en P.megakarya y $P$. palmivora, método que permite el conteo cromosómico entre las dos especies de Phytophthora.

\section{MATERIALES Y MÉTODOS}

Las técnicas utilizadas en esta investigación fueron: obtención de material fúngico para el estudio cromosómico y visualización de los cromosomas en es- tado metafase en el interior de las oosporas, incluyendo la tinción de los cromosomas con la coloración DAPI y la fijación.

Obtención de material fúngico.Tres cruzamientos de Phytophthora fueron utilizados: dos de P. megakarya, (NGR 20 x NS 203) (NGR 20 x M184) y uno de P. palmivora (TRI1x P881).

Los parámetros en estudios fueron: efecto de la consistencia del medio de cultivo "agar-zanahoria" con y sin $\beta$-sitosterol (líquido, semi-líquido al $5 \%$, sólido); efecto del soporte (lámina porta objeto, cajas de Petri y tubos de ensayos); efecto de temperatura (20 y $24^{\circ} \mathrm{C}$ ), efecto del tiempo de formación de las oosporas después de la confrontación de los micelios de apareamiento denominados A1 y A2, durante los 3, 4, 5,10 y 16 días.

Visualización de los cromosomas en estado metafase en el interior de las oosporas

Tinción de los cromosomas con la coloración DAPI.- Las oosporas fueron coloreadas con diamino -4, 6-phenylindol - 2 dichlorhydrate (DAPI), una molécula fluorescente capaz de ligarse en el ADN, permitiendo detectarlo y cuantificarlo. Fue probada la concentración $20 \mu \mathrm{l} / \mathrm{ml}$ de DAPI a $1.5 \mu \mathrm{g} / \mathrm{ml}$, en varios periodos de exposición: $20,30,40$, y 60 minutos, a una temperatura ambiente de $24^{\circ} \mathrm{C}$. 
Fijación.- Las oosporas desarrolladas en medio de zanahoria semilíquido al 5\% y sujetas en porta objetos fueron fijadas en una solución de "aldehído glutárico" al 5\%, durante 15 y 30 minutos, a temperatura ambiente de $24^{\circ} \mathrm{C}$.

Recopilación de datos.- Se prepararon cien placas, para examinar un total de 100 imágenes. Se capturaron aquellas donde se observaron las mejores células en cada fase. Las microfotografías fueron tomadas con una cámara fotográfica incluida en un microscopio fluorescente "Olympus BX 60" filtro DAPI con un aumento de 40 X y 100 X. Después de la captura de la imagen se realizó el conteo de cromosomas en 100 oosporas por especie.

\section{RESULTADOS Y DISCUSIÓN}

El estudio cromosómico permitió conocer el proceso de división meiótico en las dos especies de Phytophthora: P. megakarya y P. palmivora; y nuevas técnicas citológicas fueron adaptadas para estas especies. La estructura de reproducción sexual de los Oomycetes denominada oosporas, es el único órgano donde los cromosomas se individualizan. Durante la metafase de la meiosis los cromosomas son visibles en las oosporas y fáciles para su conteo como lo mencionan otros autores (3).

Obtención de material fúngico.Los dos cruzamientos de $P$. megakarya: NGR20 x NS203 y NGR20 x M184 desarrollados en medio de cultivo "agar- zanahoria" en consistencia semilíquida al $5 \%$, con $\beta$-sitosterol, colocados en láminas de porta objeto a una temperatura de $20^{\circ} \mathrm{C}$, a la oscuridad, produjeron fuerte concentración de oosporas al tercer día de confrontar los micelios compatibles A1xA2.

En el caso de $P$. palmivora: TRI1xP881, este cruzamiento presentó alta concentración en medio de cultivo "agar-zanahoria" en consistencia semilíquida al $5 \%$, con $\beta$-sitosterol, colocadas en láminas de porta objeto a temperatura de $20^{\circ} \mathrm{C}$, en la oscuridad.

Mientras que en medio de cultivo "agar-zanahoria" en consistencia sólida colocadas en cajas de Petri a la oscuridad a $20^{\circ} \mathrm{C}$, presentó baja concentración de oosporas y alta de esporas asexuales (esporangios y clamidospora). Las otras condiciones probadas no permitieron obtener cantidad suficiente de oosporas (Figura 1).

Visualización de los cromosomas en estado metafase en el interior de las oosporas

Tinción de los cromosomas con la coloración DAPI.- El estudio microscópico de las células meióticas con la utilización de la coloración permitió conocer el proceso de división de la meiosis $\mathrm{y}$ cuantificar el número de cromosomas de las dos especies del género Phytophthora. La técnica que permitió visualizar los cromosomas en estado metafase en el interior de las oosporas fue la 
exposición de los cromosomas con el DAPI durante 40 minutos a temperatura ambiente, en oscuridad. La coloración y el tamaño extremadamente pequeño de los cromosomas son factores que han limitado los estudios citogenéticos (7).

Fijación.- La solución del aldehído glutárico al 5\%, durante 15 minutos proporcionó buenos resultados en la interrupción de los procesos vitales de la célula sin dañar sus estructuras, así como lo describen también otros autores (8).

Números Cromosómicos.- Los cromosomas son reconocidos por su importancia en el estudio taxonómico y evolutivo. El número cromosómico proporciona datos relevantes para la solución de problemas taxonómicos y la comprensión de las tendencias evolutivas (9).

Tres días después de la confrontación de los micelios compatibles A1xA2 de $P$. megakarya se encontraron diferentes fases de la meiosis al interior de las oosporas y cinco días fueron necesarios para P. palmivora. Los cromosomas en estado metafase pueden contarse, siendo de 5 a 6 en $P$. megakarya y de 10 a 12 en $P$. palmivora. Sin embargo, los cromosomas de esta última especie no fueron bien definidos debido a la aparición de puentes de cromatina no diferenciada y por su tamaño extremadamente pequeño, los que se confundía muchas veces con partículas del colorante, como mencionan otros autores (10).
En las oosporas (órgano reproductor sexual de Phytophthora) se visualizaron diferentes estados de la meiosis, concordando con otros autores (11). Se hicieron las observaciones de los diferentes estadíos de la meiosis de Phytophthora: oospora multinucleada, degeneración nuclear, presencia de la profase I; reducción del número de núcleos, pro-metafase I; metafase (cromosomas visibles); y la formación de la oospora madura. (Figura 2)

En el micelio se observó la división nuclear, el estiramiento y la migración de dos masas cromáticas hacia las extremidades de las hifas. Este modo de división parece caracterizarse por la persistencia de la membrana nuclear y la no-individualización de los cromosomas. M. Ducamp (comunicación personal, $1^{\circ}$ de septiembre 2009, Fitopatólogo del CIRAD) opina que por esta razón, no es posible utilizar ni el micelio, ni las esporas asexuales (esporangio y clamidospora) de este género de Phytophtho$r a$ para el estudio citogenético.

La variación presentada en los números cromosómicos dentro de $P$. megakarya y $P$. palmivora indica la importancia de los cambios cromosómicos numéricos en la diversificación de las especies de este género, posiblemente debido a causas, entre ellas medioambientales, que aún no están muy claras (12). La diversidad de números cromosómicos juega un rol importante en la 


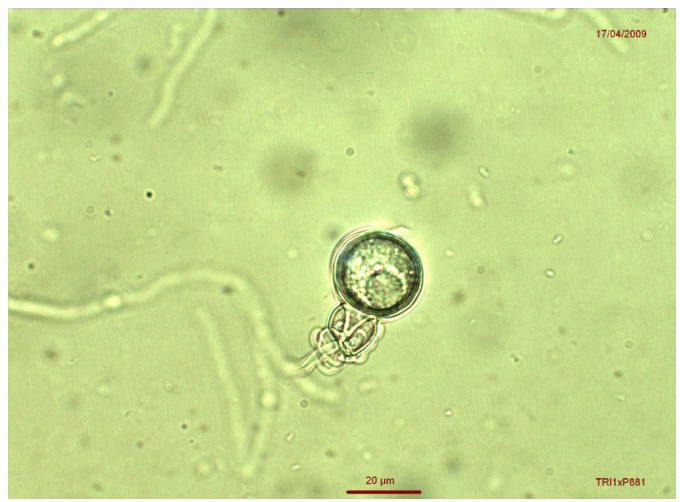

P. palmivora

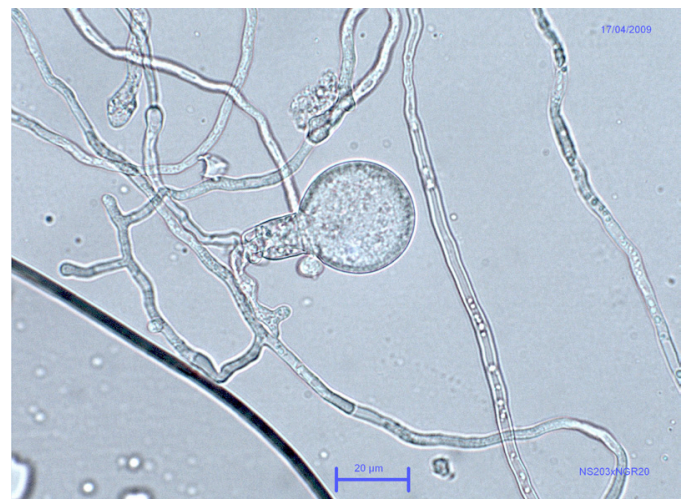

P. megakarya

Figura 1. Órgano reproductor sexual (Oosporas) de P. palmivora y P. megakarya
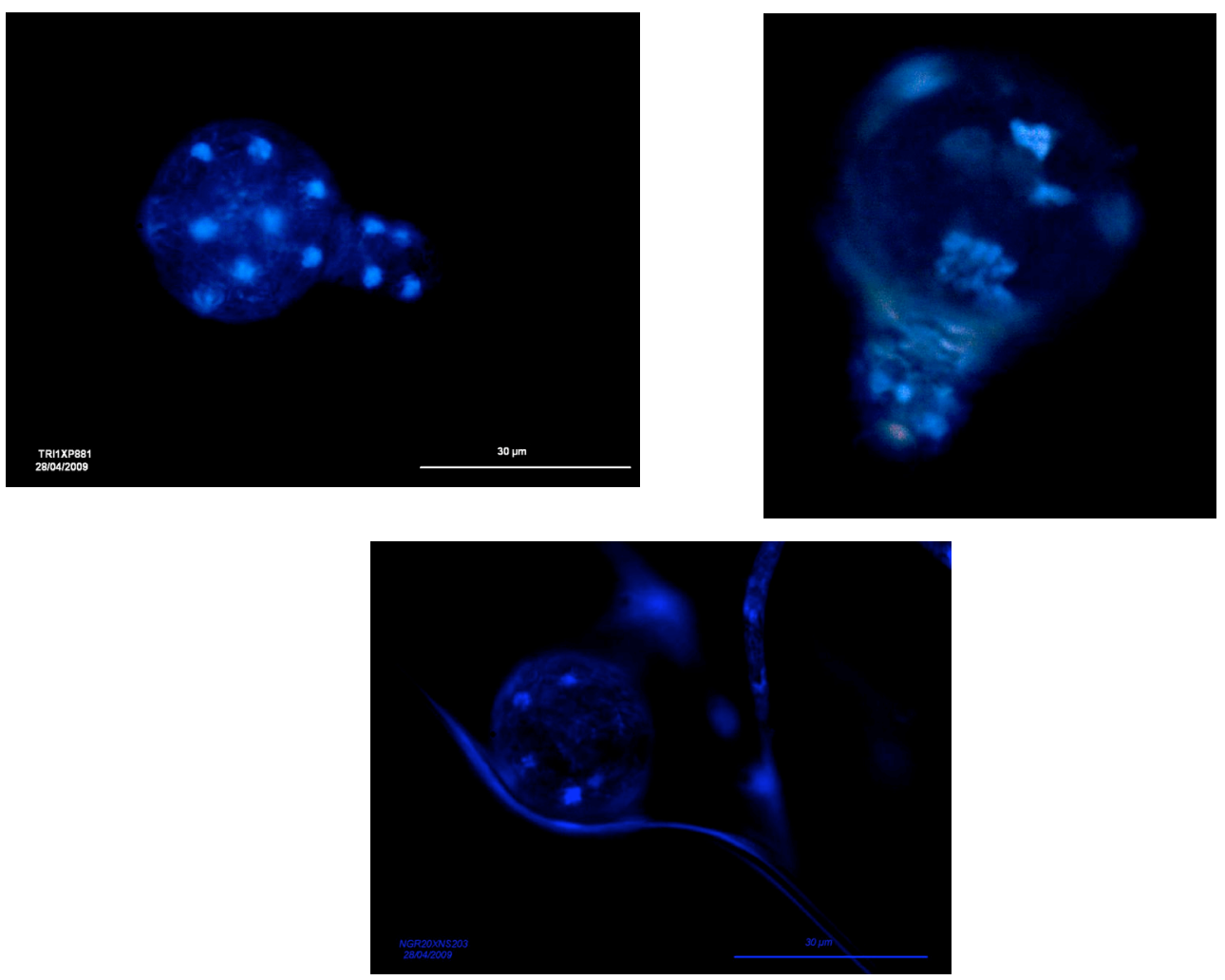

Figura 2. Algunas de las fases mitóticas observadas en P. megakarya y P. palmivora. (a) oosporas multinucleada en $P$. palmivora, (b) Profase en P. palmivora, (c) Metafase en P. megakarya. 
evolución del género Phytophthora, así como en otros, lo cual lo convierte también en un género atractivo para el análisis de dichos eventos (13).

\section{CONCLUSIONES}

Esta investigación presenta por primera vez una metodología para la visualización y el conteo cromosómico, así como también para la obtención de fases celulares en las especies de $P$. megakarya y $P$. palmivora, agentes causales de la enfermedad "Mazorca Negra" en cacao, provenientes de Camerún, África.

Las técnicas citológicas utilizadas para el conteo cromosómico en el interior de las oosporas de P. megakarya y P. palmivora, no se basó en un protocolo específico, sino en los estudios del cariotipo de $P$. parasítica.

La utilización del DAPI permitió obtener una tinción adecuada de los cromosomas, de las fases celulares y citoplasmática de las oosporas. Esta técnica permitió hacer el conteo cromosómico en el estado "metafase" siendo de 5 a 6 en $P$. megakarya y de 10 a 12 en $P$. palmivora. Sin embargo, es necesario mejorar la técnica de separación de las esporas sexuales con las asexuales de P. palmivora. Además se recomienda utilizar un agente inhibidor de la meiosis, para obtener mejores resultados en la visualización de la metafase y facilitar el conteo de cromosomas.
Con el propósito de contribuir al conocimiento de la evolución genética a partir de la fusión cromosómica de $P$. palmivora, es imperioso desarrollar técnicas moleculares como la "cuantificación del ADN de P. palmivora y P. megakarya por citometría de flujo" lo que confirmaría que $P$. megakarya posee la misma cantidad de ADN que $P$. palmivora con dos veces menor de la cantidad de cromosomas.

Se sugiere además la utilización del método FISH y un estudio de los cromosomas con un mayor número de poblaciones para establecer las relaciones entre el número de cromosomas y su localización geográfica, hábitat, etc.

\section{AGRADECIMIENTOS}

Este estudio se realizó gracias al apoyo de los laboratorios de fitopatología UMR BGPI y de citología molecular UMR DAP, del Centro de Cooperación Internacional en Investigación Agronómica para el Desarrollo (CIRAD-Francia).

\section{REFERENCIAS \\ BIBLIOGRÁFICAS}

1. ICCO Quarterly Bulletin of Cocoa Statistics. 2010. Vol. XXXVII, No. 1, Cocoa year 2010/11.

2. CILAS, C.; \& DESPRÉAUX, D. 2004. Improvement of cocoa tree resistance to Phytophthora diseases. CIRAD-DIC, Francia. 171 pp. 
3. SANSOME E.; \& BRASIER, C. 1975. Chromosomes size differences in Phytophthora palmivora, a pathogen of cacao. Nature, 255: 704-705.

4. PÉREZ, R. ET AL.; HERNANDEZ, M.; ROSE, V.; CALLEROS, V.; \& PANZERA, F. 2003. Citotaxonomía y evolución cromosómica en Triatominae, insectos vectores de la enfermedad de Chagas (heteropterareduviidae). Entomology Vector, 10: 543-550.

5. TUNA, M.; VOGEL, P.; ARUMUGANATHAN, K.; \& GILL, S. 2001. DNA content and pliody determination of bromegrass germplasm accessions by flow cytometry. Crp Science, 41: 1629 - 1634.

6. TALLEDO, D.; ESCOBAR, E.; \& ALLEMAN, V. 1995. El ciclo celular en vegetales; su estudio, importancia y aplicaciones. Biotempo, 2: 13-31.

7. SCHMIDT-LEBUHN, A.; FUCHS, L.; HERTE, D.; HIRSCH, H.; TOIVONEN, J.; \& KESSLER, M. 2010. An Andean radiation: Polyploidy in the tree genus Polylepis (Rosaceae, Sanguisorbeae). Plant Biology. Publicado on line Feb 2010.

8. SCHIMOTSUMA, M. 1961. Chromosome number of Citrullus species. Chromosome information service 2, Kyushu, Kukuoka, Japan.
10. HOCH, G.; \& KÖRNER, C. 2005. Growth, demography and carbon relations of Polylepis trees at the world's highest tree line. Functional Ecology, 19, 941951.

11. JARA-SEGUEL, P.; ROMEROMIERES, M.; \& PALMA-ROJAS, C. 2006. Chromosome numbers of Chilean pteridophytes: First contribution. Guyana Botany, 63, 115118.

12. HUGUENIN, B. ; \& BOCCAS, B. 1970. Etude de la caryocinèse chez le Phytophthora parasitica. Acad. Sc. Paris, 271: 660-663.

13. QUIJA-LAMINA, P.; SEGOVIASALCEDO, C.; JADÁN, M.; \& PROAÑO, K. 2010. Estandarización de la metodología para el conteo cromosómico en especies del género Polylepis en el Ecuador. Revista Ecuatoriana de Medicina y Ciencias Biológicas. 31: 33-49.

14. IDEHEN, E.; KEHINDE, O.; \& ADEGBITE, A. 2006. Somatic chromosome counts and yields performance of some accessions of 'egusi'melon (Citrullus lanatus). African Journal of Biotechnology 5, 2049-2052. 